\title{
Quantifying the impact of physical distance measures on the transmission of COVID-19 in the UK
}

Christopher I. Jarvis ${ }^{1 * \dagger}$, Kevin Van Zandvoort ${ }^{1 \dagger}$, Amy Gimma ${ }^{1}$, Kiesha Prem', CMMID COVID-19 working group, Petra Klepac ${ }^{1}$, G. James Rubin ${ }^{2}$ and W. John Edmunds ${ }^{1}$

\begin{abstract}
Background: To mitigate and slow the spread of COVID-19, many countries have adopted unprecedented physical distancing policies, including the UK. We evaluate whether these measures might be sufficient to control the epidemic by estimating their impact on the reproduction number $\left(R_{0}\right.$, the average number of secondary cases generated per case).

Methods: We asked a representative sample of UK adults about their contact patterns on the previous day. The questionnaire was conducted online via email recruitment and documents the age and location of contacts and a measure of their intimacy (whether physical contact was made or not). In addition, we asked about adherence to different physical distancing measures. The first surveys were sent on Tuesday, 24 March, 1 day after a "lockdown" was implemented across the UK. We compared measured contact patterns during the "lockdown" to patterns of social contact made during a non-epidemic period. By comparing these, we estimated the change in reproduction number as a consequence of the physical distancing measures imposed. We used a meta-analysis of published estimates to inform our estimates of the reproduction number before interventions were put in place.

Results: We found a $74 \%$ reduction in the average daily number of contacts observed per participant (from 10.8 to 2.8). This would be sufficient to reduce $R_{0}$ from 2.6 prior to lockdown to 0.62 ( $95 \%$ confidence interval [Cl] 0.37 0.89) after the lockdown, based on all types of contact and $0.37(95 \% \mathrm{Cl}=0.22-0.53)$ for physical (skin to skin) contacts only.

Conclusions: The physical distancing measures adopted by the UK public have substantially reduced contact levels and will likely lead to a substantial impact and a decline in cases in the coming weeks. However, this projected decline in incidence will not occur immediately as there are significant delays between infection, the onset of symptomatic disease, and hospitalisation, as well as further delays to these events being reported. Tracking behavioural change can give a more rapid assessment of the impact of physical distancing measures than routine epidemiological surveillance.
\end{abstract}

Keywords: COVID-19, Contact survey, Pandemic, Disease outbreak, Reproduction number, nCov

\footnotetext{
* Correspondence: Christopher.Jarvis@lshtm.ac.uk

${ }^{\dagger}$ Christopher I. Jarvis and Kevin van Zandvoort contributed equally to this work.

${ }^{1}$ Centre for Mathematical Modelling of Infectious Diseases, Department of Infectious Disease Epidemiology, London School of Hygiene \& Tropical Medicine, Keppel Street, London WC1E 7HT, UK

Full list of author information is available at the end of the article
}

(c) The Author(s). 2020 Open Access This article is licensed under a Creative Commons Attribution 4.0 International License, which permits use, sharing, adaptation, distribution and reproduction in any medium or format, as long as you give appropriate credit to the original author(s) and the source, provide a link to the Creative Commons licence, and indicate if changes were made. The images or other third party material in this article are included in the article's Creative Commons licence, unless indicated otherwise in a credit line to the material. If material is not included in the article's Creative Commons licence and your intended use is not permitted by statutory regulation or exceeds the permitted use, you will need to obtain permission directly from the copyright holder. To view a copy of this licence, visit http://creativecommons.org/licenses/by/4.0/. The Creative Commons Public Domain Dedication waiver (http://creativecommons.org/publicdomain/zero/1.0/) applies to the data made available in this article, unless otherwise stated in a credit line to the data. 


\section{Background}

Over 1.8 million cases and over 110,000 deaths from COVID-19 have been recorded worldwide as of 13 April 2020 [1]. A major route of transmission of SARS-CoV2 is via droplet spread which requires close contact [2]. In an attempt to mitigate the COVID-19 pandemic, many countries have adopted unprecedented physical distancing policies [3]. On March 23, with just over 6000 confirmed cases, the UK Government implemented strict physical distancing measures instructing individuals to stay at home and avoid leaving their house except for essential work, to take one form of exercise a day, and to buy essential items such as food and medicines. This followed the closure of sporting events, schools, restaurants, bars, gyms, and other leisure or hospitality-related businesses the previous week [4] and an increase in social distancing among the population that had been taking place for several days before the announcement [5].

Physical distancing interventions attempt to reduce contacts relevant to infectious disease spread between individuals. Multiple surveys have been instigated on the uptake of different physical distancing measures during this current pandemic, but these have not explicitly measured contacts between people [6-8]. To make accurate predictions on the impact of these measures, quantitative data on relevant contact patterns is required [9-12]. Many governments have adopted physical distancing measures to mitigate the impact of the COVID-19 pandemic. However, it is unclear to what extent these measures reduce the number of contacts and therefore transmission. Only one previous survey-conducted in two Chinese cities, Wuhan and Shanghai, in February 2020-quantified the impact of these measures on individuals' contact patterns during the COVID-19 pandemic [13].

Changes in human contact behaviour drive respiratory infection rates. Understanding these changes at different stages of the COVID-19 pandemic allows us to rapidly quantify the impact of physical distancing measures on the transmission of pathogens. In this paper, we describe a survey of contact patterns and compliance with physical distance measures and present results from a sample of adults in the UK. We evaluate whether these measures might be sufficient to control the epidemic by estimating their impact on the reproduction number (the average number of secondary cases generated per case).

\section{Methods}

\section{Ethics statement}

Participation in this opt-in study was voluntary, and all analyses were carried out on anonymised data. The study was approved by the ethics committee of the London School of Hygiene \& Tropical Medicine reference number 21795.

\section{Survey methodology}

We commissioned the market research company Ipsos to conduct a survey of UK adults (referred to here as the CoMix survey). Adults ( $\geq 18$ years) were recruited into the survey by sending email invitations to existing members of their online panel. Representativeness of the general UK population was ensured by setting quotas on age, gender, geographical location, and socioeconomic status. This cohort of individuals will be requested to answer the survey every 2 weeks for a total of 16 weeks to track changes in their self-reported behaviour. The first surveys were sent on Tuesday, 24 March, 1 day after a lockdown was announced for the UK.

Participants were asked about their attitudes towards COVID-19 and the effect of physical distancing interventions, whether they or any of their household members experienced any recent symptoms, whether they were tested for COVID-19, whether they had had any contact with known COVID-19 cases, and whether they were affected by physical distancing measures.

Participants reported (i) if any person in their household were advised to quarantine, isolate, or limit time in their workplace or educational facility in the preceding 7 days due to COVID-19 and (ii) if they heeded the advice and isolated, quarantined, or stayed away from their workplace or educational facility. In the survey, we defined quarantine as limiting contacts and staying at home, with restricted allowance for movement outside the home after a potential exposure with a COVID-19 case. We defined isolation as completely separating from uninfected contacts, including household members, either in the home or in a health facility. To assess the impact of advice and policy changes regarding physical distancing, we asked participants to indicate if they had planned to participate in a set of events in the preceding week. For each event type, they reported (i) whether they proceeded with their plan, or (ii) if it was cancelled or they decided not to go, and (iii) the frequency of the event type in the previous 7 days. Additional questions were asked about preventive behaviours, such as handwashing or wearing masks, and about the use of public transport in the previous 7 days.

In addition, we asked participants to record all direct contacts made between 5 am the day preceding the survey and 5 am the day of the survey. A direct contact was defined as anyone who was met in person and with whom at least a few words were exchanged, or anyone with whom the participants had any sort of skin-to-skin contact. We were unable to ask parents to provide contact information for their children due to lack of ethical approval; however, participants were able to list contacts who were under 18.

For every recorded contact, participants documented the age and gender of the contact, relationship to the 
contact, the frequency with which they usually contact this person, whether contact was physical (skin to skin) or not, and the setting where the contact occurred (e.g. at home, work, school, or whilst undertaking leisure activities), including whether contact occurred in- or outside an enclosed building. Questions on social contacts were consistent with those from the UK arm of the POLYMOD survey [14], which was used as the baseline pre-pandemic comparison dataset. Details on survey methodology, the study protocol, and a copy of the questionnaire used are provided in Additional files 1 and 2.

\section{Statistical analysis}

$R$ version 3.6.3 was used for all analyses; the code and data are available on github (see the "Availability of data and materials" section) [15-17].

We grouped study participants and contacts into the following age bands: $18-29,30-39,40-49,50-59,60-$ 69 , and 70+. Age, gender, and locations of participants were compared to the 2018 mid-year estimates provided by the UK Office of National Statistics (ONS) to assess the representativeness of the study sample [18]. We descriptively analysed answers related to symptoms, attitudes, exposure to physical distancing measures, and individual preventative measures. We present the number and percentage or mean and standard deviation where appropriate (Table 3).

We calculated the average number of social contacts per person per day overall, and stratified by age category, sex, household size, location of contact, type of contact, and day of the week. We then compared the mean total number of daily contacts by age group to POLYMOD stratified by contact location.

We calculated social contact matrices for the agespecific daily frequency of direct social contacts, adjusting for the age distribution in the study population and reciprocity of contacts, using the socialmixr package in $\mathrm{R}$ [19].

As children $(<18$ years) were not included as survey participants, we imputed contacts for younger age groups (child-child and child-adult contacts) using the POLYMOD UK data. Specifically, for those child contact groups that were missing, we used a scaled version of the POLYMOD social contact matrix. Following previous methods developed by Klepac et al. [20], as the scaling factor, we took the ratio of the dominant eigenvalues of the POLYMOD and CoMix matrices, for all age groups present in both studies, stratified by setting. Furthermore, to reflect school closures during the collection of our survey, we removed school contacts from the POLYMOD data from our analysis.

The basic reproduction number, or $R_{0}$, is the average number of secondary infections arising from a typical single infection in a completely susceptible population and can be estimated as the dominant eigenvalue of the next generation matrix [21]. The exact form of the next generation matrix is model dependent. For respiratory infections, such as SARS-CoV-2 (the pathogen causing COVID-19), this is usually a function of the age-specific number of daily contacts, the probability that a single contact leads to transmission, and the total duration of infectiousness. Therefore, $R_{0}$ is proportional to the dominant eigenvalue of the contact matrix [19].

We assumed that contact patterns prior to physical distancing were similar to those observed in the POLYMOD data and that the duration of infectiousness and the probability that a single contact leads to transmission did not change during the study period. We also assume that all age groups contribute equally to transmission. Under these assumptions, the relative reduction in $R_{0}$ is equivalent to the reduction in the dominant eigenvalue of the contact matrices. By multiplying the value of $R_{0}$ prior to the interventions by the ratio of the dominant eigenvalues from the POLYMOD and CoMix contact matrices, we were able to calculate $R_{0}$ under the physical distancing interventions. Prior to interventions, we assumed $R_{0}$ followed a normal distribution with mean 2.6 and standard deviation of 0.54 based on a meta-analysis of the literature presented in Additional file 3 [22-34].

To assess uncertainty, we repeated the age imputation process by taking 10,000 bootstrapped samples from both POLYMOD and CoMix matrices. For every bootstrap sample, we calculated the ratio between the dominant eigenvalues for the sampled POLYMOD and CoMix matrices. This sampling provided a distribution of relative change in $R_{0}$ from the contact patterns observed in POLYMOD and CoMix. Subsequently, we scaled the initial distribution of $R_{0}$ with the distribution of bootstrap samples to estimate $R_{0}$ under physical distancing interventions.

Recent results of the BBC Pandemic study [20] suggested a decrease of nearly $50 \%$ in the average number of contacts made by teenagers (13-18 years) compared with the POLYMOD data. We assessed the sensitivity of our results to a potential reduction in contacts over time by taking a conservative reduction of $50 \%$ between 5 and 18 year olds in the POLYMOD study and repeating our approach to estimate the reduction in $R_{0}$.

\section{Results}

\section{Participant characteristics}

We surveyed 1356 UK participants who recorded 3849 contacts. The average age of participants was 47.2 years (standard deviation $(\mathrm{SD})=15, \max =86)$, and 45\% (608/ 1356) were female (see Table 1). The average household size was $2.8(\mathrm{SD}=1.4, \max =10)$. Data were collected between Tuesday 24 and Friday 27 March 2020 inclusive. 
Table 1 Participant characteristics in the CoMix survey, and comparison with 2018 mid-year UK population estimates provided by the Office of National Statistics. The CoMix survey does not include children under the age of 18

\begin{tabular}{|c|c|c|}
\hline & Number of participants (\%)* & UK ONS mid-year Estimate \\
\hline \multicolumn{3}{|l|}{ Location $(N=1240)$} \\
\hline North of England & $198(16.0 \%)$ & $23.2 \%$ \\
\hline Midlands and East of England & $328(26.5 \%)$ & $25.4 \%$ \\
\hline London & $205(16.5 \%)$ & $13.4 \%$ \\
\hline South of England & $302(24.4 \%)$ & $22.2 \%$ \\
\hline Wales & $54(4.4 \%)$ & $4.7 \%$ \\
\hline Scotland & $121(9.8 \%)$ & $8.2 \%$ \\
\hline Northern Ireland & $32(2.6 \%)$ & $2.8 \%$ \\
\hline Missing & 116 & - \\
\hline \multicolumn{3}{|l|}{ Age group $(N=1356)^{* *}$} \\
\hline $0-9$ & 0 & - \\
\hline $10-19$ & $28(2.1 \%)$ & - \\
\hline $20-29$ & $185(13.6 \%)$ & $17.1 \%$ \\
\hline $30-39$ & $275(20.3 \%)$ & $17.4 \%$ \\
\hline $40-49$ & $249(18.4 \%)$ & $16.7 \%$ \\
\hline $50-59$ & $233(17.2 \%)$ & $17.6 \%$ \\
\hline $60-69$ & $280(20.7 \%)$ & $13.9 \%$ \\
\hline $70+$ & $106(7.8 \%)$ & $17.3 \%$ \\
\hline Missing & 0 & - \\
\hline \multicolumn{3}{|l|}{ Gender $(N=1356)$} \\
\hline Males & $748(55.2 \%)$ & $49.4 \%$ \\
\hline Females & $608(44.8 \%)$ & $50.6 \%$ \\
\hline Missing & 0 & - \\
\hline
\end{tabular}

*Within-group percentages

**There are no individuals aged less than 18 in the survey participants; therefore, we only compare the percentages of age groups that are fully observed in the study from the ONS mid-year estimates

Participants were recruited from across the UK. The sample included participants from London (16.5\%), North of England (16.0\%), Midlands and East of England (26.5\%), South of England (24.4\%), Wales (4.4\%), Scotland (9.8\%), and Northern Ireland (2.6\%), whilst 116 participants did not report their region (Table 1). Further details of participant demographics and the average number of contacts stratified by age, gender, household size, and location are presented in Table 2. Compared to the mid-year ONS population estimates taken from 2018 , individuals over 70 years and individuals between the ages of 20-29 years were undersampled.

Thirteen participants reported having been tested for COVID-19 with seven testing positive, and two participants still waiting for their results. Forty-one participants stated they had been in contact with a known COVID19 case. In terms of perceived risk, 26.4\% (359/1356) thought that it was likely that they would develop coronavirus and 48.0\% (652/1356) agreed or strongly agreed that COVID-19 would be a serious disease for them if they acquired the infection.

\section{Impact of physical distancing measures}

Participants reported data on a total of 3824 household members, including themselves, of whom 508 (13.2\%) had been asked to quarantine and 826 (21.6\%) had been asked to isolate. Nearly a quarter $(921 ; 24.1 \%)$ of household members lived in a house with someone who had at least one symptom of fever, aches, shortness of breath, or cough. Roughly $50 \%$ of the 2122 employed individuals had either been asked to limit their time at work, had their work closed, and/or did not visit their work in the preceding 7 days (Table 3). Of those household members who attend educational establishments, $67.2 \%$ (818/1217) had their institution closed with $63.3 \%$ not visiting during the previous 7 days.

There were clear suggestions that physical distancing in the previous week had impacted planned activities for survey participants with $51.3 \%$ of participants that intended to go to a concert being unable as the event was cancelled, $40.6 \%$ intending to go to the cinema were unable as the cinema was closed, and $32.5 \%$ of participants having to cancel plans to visit a pub (Table 3). Contrastingly, only a small percentage of participants 
Table 2 Number of recorded contacts per participant per day stratified by age, gender, household size, and day of the week

\begin{tabular}{|c|c|c|c|c|}
\hline Category & Value & Number of participants & CoMix reported contacts, mean (IQR) & POLYMOD reported contacts, mean (IQR \\
\hline \multirow[t]{7}{*}{ Overall } & Overall & 1356 & $2.8(1,4)$ & $10.8(6,14)$ \\
\hline & $18-29$ & 213 & $3.0(1,4)$ & $12.1(7,16)$ \\
\hline & $30-39$ & 275 & $3.1(1,4)$ & $11.3(6,15)$ \\
\hline & $40-49$ & 249 & $3.1(1,4)$ & $12.0(6,17)$ \\
\hline & $50-59$ & 233 & $3.0(1,4)$ & $9.5(5,13)$ \\
\hline & $60-69$ & 280 & $2.5(1,3)$ & $9.0(5,12)$ \\
\hline & $70+$ & 106 & $2.0(1,3)$ & $7.6(4,12)$ \\
\hline \multirow[t]{2}{*}{ Gender of participant } & Female & 608 & $2.9(1,4)$ & $11.3(6,15)$ \\
\hline & Male & 748 & $2.8(1,4)$ & $10.2(5,13)$ \\
\hline \multirow[t]{5}{*}{ Household size } & 1 & 203 & $1.6(1,2)$ & $7.4(3,11)$ \\
\hline & 2 & 431 & $2.3(1,3)$ & $10.1(5,13)$ \\
\hline & 3 & 363 & $2.7(2,3)$ & $11.2(6,15)$ \\
\hline & 4 & 207 & $4(3,4)$ & $12.1(7,16)$ \\
\hline & $4+$ & 152 & $4.7(4,6)$ & $14.2(9,17)$ \\
\hline \multicolumn{5}{|l|}{ Date } \\
\hline 24 March 2020 & Tuesday & 178 & $3.0(1,43)$ & - \\
\hline 25 March & Wednesday & 1014 & $2.8(1,4)$ & - \\
\hline 26 March & Thursday & 162 & $2.9(1,3)$ & - \\
\hline 27 March & Friday & 2 & $5.0(5,5)$ & - \\
\hline
\end{tabular}

(2.5\%) who intended to go to the supermarket were unable due to COVID-19.

\section{Contact patterns}

The mean number of physical (skin to skin) and nonphysical contacts per person measured during this study was 2.8 (interquartile range $[\mathrm{IQR}]=1-4$ ) which was $74 \%$ lower than was measured in POLYMOD (10.8; 6-14). The reduction in mean contacts between POLYMOD and CoMix was consistent across age, gender, and household size (Table 2). The respective social contact matrices (including physical and non-physical contacts)

Table 3 Indicators of adherence with public health interventions and behaviour changes for all household members reported by participants

\begin{tabular}{|c|c|c|c|c|}
\hline \multirow{2}{*}{$\begin{array}{l}\text { Measure } \\
\text { Quarantine }(N=3824)\end{array}$} & \multirow{2}{*}{$\begin{array}{l}\text { Asked to } \\
508(13.2 \%)\end{array}$} & \multirow{2}{*}{$\begin{array}{l}\text { Have been in } \\
778(20.3 \%)\end{array}$} & \multicolumn{2}{|c|}{ At least with COVID-19 symptom } \\
\hline & & & Living in a household & $921(24.1 \%)$ \\
\hline Isolation $(N=3824)$ & $826(21.6 \%)$ & $1264(33.1 \%)$ & People & $462(12.1 \%)$ \\
\hline Setting & Asked to limit time & Reported as closed & Did not visit & \\
\hline Work $(N=2122)$ & $1006(47.4 \%)$ & $996(46.9 \%)$ & $1149(54.1 \%)$ & \\
\hline School or university $(N=1217)$ & $651(47.4 \%)$ & $818(67.2 \%)$ & $771(63.3 \%)$ & \\
\hline Event & Intended to visit & Visited & Cancelled & Chose not to visit \\
\hline Concert & 111 & $6(5.4 \%)$ & $57(51.3 \%)$ & $20(18.1 \%)$ \\
\hline Cinema & 133 & $11(8.3 \%)$ & $54(40.6 \%)$ & $43(32.3 \%)$ \\
\hline \multicolumn{5}{|l|}{ Sporting event } \\
\hline Participant & 105 & $14(13.3 \%)$ & $46(43.8 \%)$ & $33(31.4 \%)$ \\
\hline Attendee & 100 & $9(9.0 \%)$ & $54(54.0 \%)$ & $20(20.0 \%)$ \\
\hline Restaurant & 271 & $28(10.3 \%)$ & $118(43.5 \%)$ & $100(36.9 \%)$ \\
\hline Religious event & 105 & $14(13.3 \%)$ & $68(64.7 \%)$ & $33(31.4 \%)$ \\
\hline Pub & 366 & $105(28.6 \%)$ & $119(32.5 \%)$ & $24(6.6 \%)$ \\
\hline Supermarket & 1127 & $967(85.8 \%)$ & $28(2.5 \%)$ & $112(10.0 \%)$ \\
\hline
\end{tabular}


also reflected a much lower number of mean contacts across the age strata as presented in Fig. 1.

The majority of contacts (57.6\%) occurred at home, contrasting with $33.7 \%$ reported in the POLYMOD survey. Figure 2 displays the average number of contacts across age groups for all, physical, home, work, school, and other contacts. The matrices are consistent with the majority of contacts being in the home, with work, and other contributing very little to the overall number of contacts.

\section{Estimated the basic reproduction number of COVID-19 under physical distancing}

We estimated the current $R_{0}$ under physical distancing measures to be 0.62 (95\% confidence interval [CI] 0.370.89 ) based on all types of contact (Fig. 1). Based on physical contacts only, we estimated $R_{0}$ to be 0.37 (95\%
$\mathrm{CI}=0.21-0.52)$. The average pre- to post-intervention ratio in $R_{0}$ was 0.24 ( $\left.\min =0.21, \max =0.27\right)$ for all contacts and 0.14 ( $\min =0.12, \max =0.17$ ) for physical (skin to skin) contacts only. Based on these values, the physical distancing measures would have reduced the mean estimate of $R_{0}$ to below one even if the initial $R_{0}$ had been as high as 3.6 assuming all contacts are equally risky or 4.2 assuming only physical contacts result in transmission.

In a sensitivity analysis, reducing contacts made by $5-17$ year olds by $50 \%$ made little difference to the results. Under this assumption, the estimated value of $R_{0}$ for all contacts would be 0.69 (95\% CI $0.42-0.98$ ) and 0.37 (95\% CI $0.22-$ 0.53 ) if physical contacts alone result in transmission.

\section{Discussion}

The measures introduced by the UK Government appear to have high levels of uptake among participants and
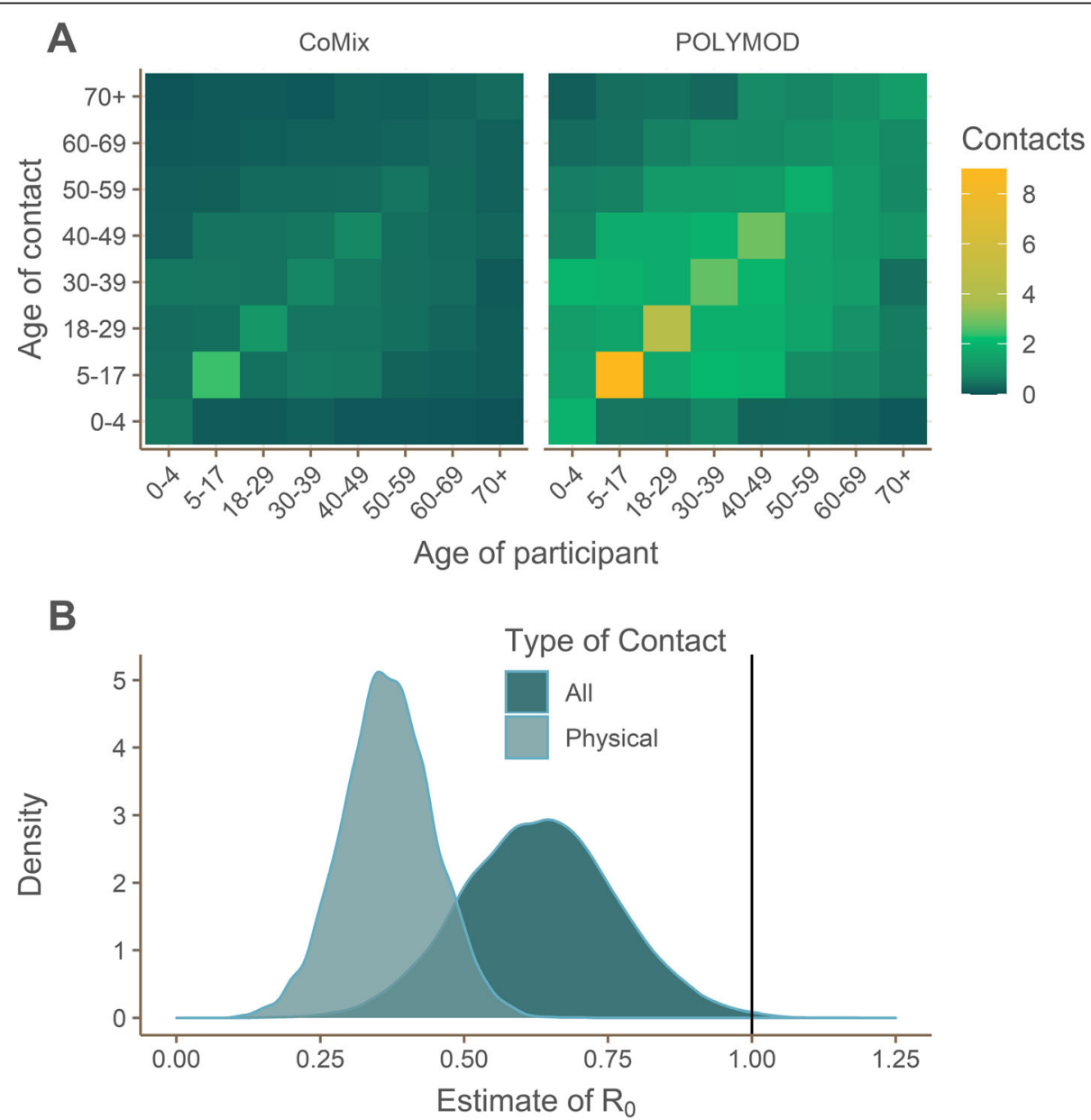

Fig. 1 Comparison of CoMix and POLYMOD contact matrices and estimated reduction in reproduction number due to physical distancing for all and physical (skin to skin) contacts separately. a Social contact matrices showing the average total number of daily reported contacts made by participants in different age groups with individuals in other age groups, with results shown for all contacts reported in the COMix and POLYMOD data. Participants' contacts in CoMix for age groups 0-4 and 5-17 are imputed using the POLYMOD data. $\mathbf{b}$ The estimated value of $R_{0}$ at the time of the survey, assuming values of $R_{0} \sim$ Norm $(2.6, \mathrm{SD}=0.54)$ prior to physical distancing reducing all contacts for all and physical (skin to skin) contacts 


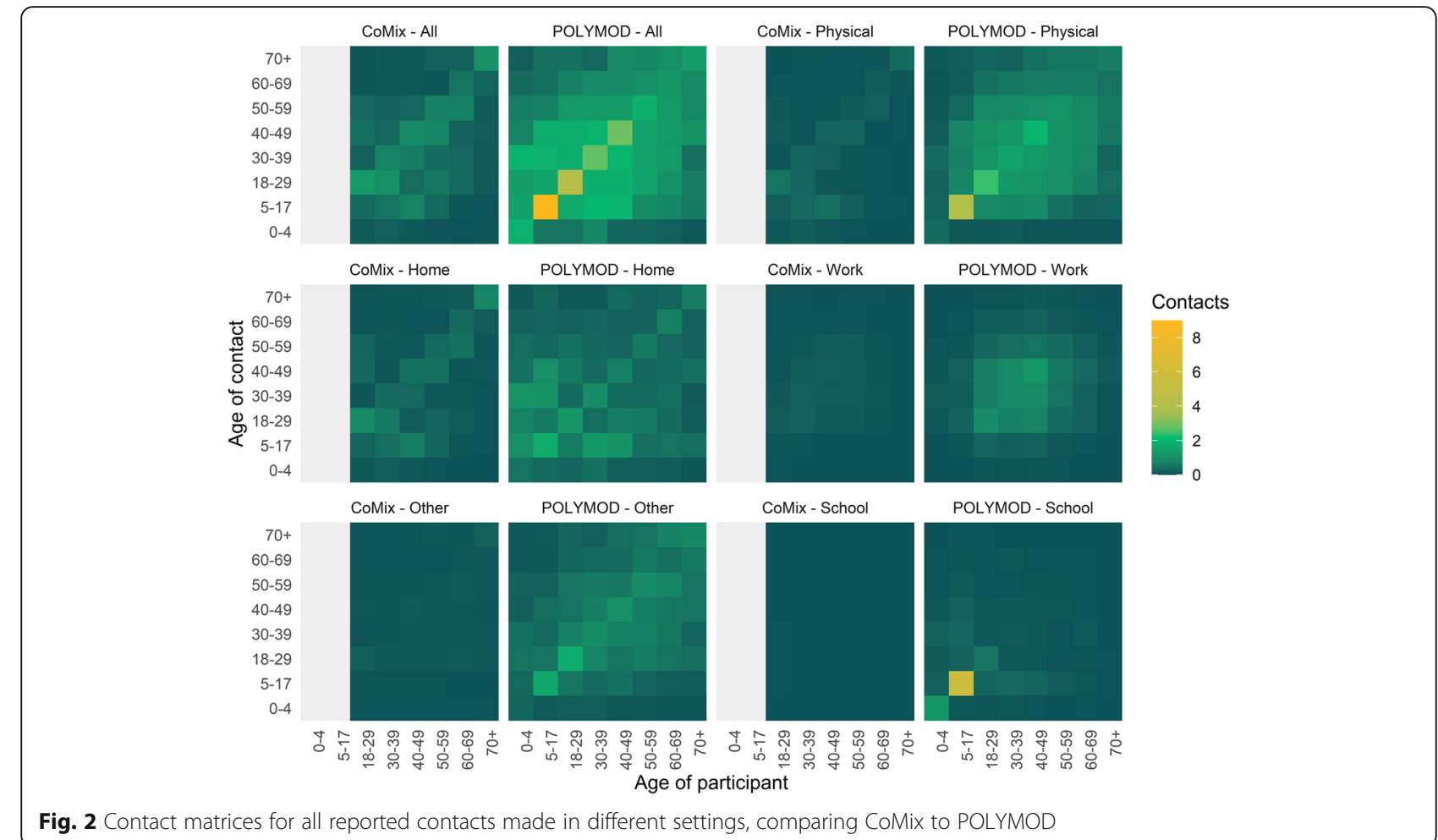

have resulted in very large (74\%) reductions in the total number of contacts. If similar changes are observed across the UK population, we would expect the basic reproduction number to now be below 1 ( 0.62 ; $95 \%$ CI $0.37-0.89)$ and that these physical distancing measures will lead to a decline in cases in the coming weeks. However, this projected decline in incidence will not result in an immediate decline in reported cases, as there are significant delays between infection and the onset of symptomatic disease and hospitalisation, as well as further delays to these events being reported. Hence, routine surveillance data are unlikely to show a decline in cases for some time. However, by directly measuring individuals' contact patterns and estimating the corresponding basic reproduction number, we are able to rapidly quantify the impact of physical distancing on transmission.

The total number of daily contacts (mean of 2.8 per person) was significantly reduced compared to patterns previously estimated in the POLYMOD study (10.7; excluding children < 18 years old) and more recently by the BBC Pandemic study (10.5; excluding under 13 year olds) [20]. The observed reduction appears to be unlikely due to chance given the large difference in average contacts and is consistent with a recent study conducted in Wuhan, China, that estimated a reduction in the average number contacts per day from 14.6 prior to the outbreak to 2.0 under physical distancing interventions [13]. Whilst we are unaware of any directly comparable data from the UK, our findings are certainly consistent with other reports from the UK of a dramatic reduction in social contacts, with, for example, only half of respondents in one survey reporting having left the house at all in the past $24 \mathrm{~h} \mathrm{[5].}$

There are several limitations to this survey. Asking individuals to report their contacts from the day before may result in recall bias. Moreover, individuals who are adhering to physical distancing measures may have been more likely to respond to this survey, potentially resulting in selection bias and in an overestimate of the impact of these measures. The POLYMOD survey used paper-based diaries whereas CoMix utilises an online form, which may have resulted in different numbers of contacts being reported in CoMix. However, it is unlikely that the large differences observed would be due only to the reporting methodology of the surveys. Furthermore, we were not able to sample any children, so child-child contacts had to be imputed from the POLYMOD survey. This weakens the comparability of the two studies, and future work is planned to directly measure child-child contacts which will help assess the impact of this limitation.

We were not able to quantify any additional effect from the interventions on transmission, such as reduction in infectiousness by increased handwashing. In addition, we were not able to calculate the net reproductive number, $R$, as we did not account for the proportion of the population that is no longer susceptible. These could all reduce the net reproductive number to 
values lower than estimated in our analysis. This approach further assumes that all age groups contribute equally to transmission, which may not be the case. Assuming flu-like transmission where children are the group most responsible for transmission, the contribution of adults to overall $R_{0}$ would be lower [9]. However, if children do not play a significant role in transmission, the significance of adult transmission will be higher. Therefore, although this survey provides evidence of overall contacts in the population reducing which will considerably lower $R_{0}$, lack of knowledge of the relative contributions of different age groups to overall transmission reduces our ability to precisely determine the exact reduction in transmission.

Our analysis assumed that direct contacts are an appropriate proxy for effective contacts, and thus, that transmissibility is equal across age groups (e.g. contact between a single infected child and susceptible adult is as likely to result in transmission as contact between a single infected adult and a susceptible adult). We further assume that the reduction in non-school contacts in children is similar to that observed in adults. Furthermore, we assume that the contact patterns prior to interventions are consistent and of similar magnitude. A recent study has found significantly lower numbers of contacts reported by teenagers compared with the POLYMOD survey [20]. Decreasing mixing among 517 years by $50 \%$, whilst reducing the magnitude of reduction in $R_{0}$, did not affect the qualitative conclusions from the analysis.

As of 13 April, the growth rate of reported cases in the UK appears to be slowing, declining from a $20 \%$ increase per day for the 5 days prior to 24 March to a $7 \%$ increase per day for the 5 days prior to 13 April [1]. This is consistent with a reduction in the reproduction number; however, it is difficult to correlate the magnitude of this reduction with the estimated value of $R_{0}$. Our approach assumes that individuals within an age group behave the same, and does not account for hospitals and other institutions which will have different disease dynamics. Moreover, due to the UK testing algorithm being focused on people in hospitals and as there seems to be an increasing problem of nosocomial infection, any decline in community infection may be counterbalanced by an increase in nosocomial infections. Given that the confirmed cases are primarily hospital based, this can have a disproportionate effect on the estimated reproduction number using crude data (i.e. not split by route of transmission). Future work is planned to compare the estimates of $R_{0}$ with the growth rate of the epidemic, accounting for changes in levels of testing, reporting, delays, and transmission context.

This study is planned to continue in the UK for the next 15 weeks and will be extended to other countries including Belgium and the Netherlands. Future analyses will be able to explore changes in contact patterns during different interventions and may provide early warning signs of changes in contact patterns due to interventions being lifted or decreasing adherence with restrictions.

\section{Conclusions}

We have shown that behavioural monitoring can give a rapid insight into transmission of COVID-19 and have provided the first evidence that the restrictions adopted by the UK Government have led to a decrease in transmission of COVID-19.

Table 3 shows compliances with different social distancing measures due to COVID-19. $N$ symptoms shows the total number of household members who were living in a household where someone had any of the following symptoms (fever, aches, shortness of breath, cough), and how many individuals reported having COVID-19 symptoms themselves. The column Asked to refers to the total number of people who reported being asked to quarantine or isolate. The column Have been in shows the total number of people who reported having been in quarantine or isolation for at least 1 day in the 7 days before the survey.

\section{Supplementary information}

Supplementary information accompanies this paper at https://doi.org/10 1186/s12916-020-01597-8.

Additional file 1. CoMix study questions.

Additional file 2. CoMix study Protocol.

Additional file 3. CoMix additional analyses.

\section{Abbreviations}

Cl: Confidence interval; IQR: Interquartile range; ONS UK: Office of National Statistics; SD: Standard deviation

\section{Acknowledgements}

$\mathrm{CIJ}$ and AG were funded by the Global Challenges Research Fund (ES/ P010873/1). KvZ was funded by Elrha's Research for Health in Humanitarian Crises [R2HC] Programme, UK Government [Department for International Development]. KP was funded by the National Institute for Health Research (NIHR; 16/137/109). PK was funded by the Bill \& Melinda Gates Foundation (INV-003174). GJR was funded by the National Institute for Health Research Health Protection Research Unit (NIHR HPRU) in Emergency Preparedness and Response at King's College London in partnership with Public Health England (PHE), in collaboration with the University of East Anglia and Newcastle University. The views expressed are those of the author(s) and not necessarily those of the NHS, the NIHR, the Department of Health and Social Care, or Public Health England.

We would like to acknowledge the other members of the London School of Hygiene \& Tropical Medicine CMMID COVID-19 modelling group, who contributed to this work. Their funding sources are as follows: Megan Auzenbergs and Kathleen O'Reilly (Bill and Melinda Gates Foundation, OPP1191821); Graham Medley (NTD Modelling Consortium by the Bill and Melinda Gates Foundation (OPP1184344)); Jon C Emery and Rein M G J Houben (European Research Council Starting Grant, Action Number \#757699); Nicholas Davies (NIHR HPRU-2012-10096); Emily S Nightingale (Bill and Melinda Gates Foundation, OPP1183986; Wellcome Trust, and NIHR); Stefan Flasche (Sir Henry Dale Fellowship 208812/Z/17/Z); Thibaut Jombart 
(Research Public Health Rapid Support Team, NIHR Health Protection Research Unit Modelling Methodology); Joel Hellewell, Sam Abbott, James D Munday, Nikos I Bosse, and Sebastian Funk (Wellcome Trust 210758/Z/18/Z) Fiona Sun (NIHR; 16/137/109); Akira Endo (The Nakajima Foundation; The Alan Turing Institute); Alicia Rosello (NIHR: PR-OD-1017-20002); Simon R Procter (Bill and Melinda Gates Foundation, OPP1180644); Fiona Sun (NIHR; 16/ 137/109); Adam J Kucharski and Timothy W Russell (Wellcome Trust, 206250/ Z/17/Z); Gwen Knight (UK Medical Research Council, MR/P014658/1); Hamish Gibbs (Department of Health and Social Care ITCRZ 03010); Quentin Leclerc (Medical Research Council London Intercollegiate Doctoral Training Program studentship grant no. MR/N013638/1); Billy J. Quilty, Charlie Diamond, Yang Liu, and Mark Jit (National Institute for Health Research NIHR; 16/137/109); Yang Liu and Mark Jit (Bill \& Melinda Gates Foundation INV-003174); Samuel Clifford (Sir Henry Dale Fellowship 208812/Z/17/Z); Carl A.B. Pearson (NTD Modelling Consortium by the Bill and Melinda Gates Foundation OPP1184344); Rosalind M. Eggo (Health Data Research UK MR/S003975/1); and Arminder K Deol. We would like to thank Paula Bianca Blomquist for thoughtful critique and discussions during this analysis. This research was partly funded by the NIHR (16/137/109) using aid from the UK Government to support global health research. The views expressed in this publication are those of the author(s) and not necessarily those of the NIHR or the UK Department of Health and Social Care. We would also like to thank the team at Ipsos who have been excellent in running the survey, collecting the data, and allowing for this study to happen at a rapid speed.

\section{Authors' contributions}

WJE, GJR, CIJ, and KvZ conceived of and designed the study. CIJ, KvZ, and WJE conceived of the analysis. CIJ, KVZ, AG, and KP conducted the analysis. $\mathrm{CIJ}$ and KVZ wrote the manuscript with input and guidance from WJE, AG, KP, GJR, and PK. The CMMID COVID-19 working group members contributed to the processing, cleaning, and interpretation of data; interpreted the study findings; contributed to the manuscript; and approved the work for publication. All authors interpreted the findings, contributed to writing the manuscript, and approved the final version for publication.

\section{Funding}

This project was funded by the European Union's Horizon 2020 Research and Innovations Programme - project EpiPose (Epidemic Intelligence to Minimize COVID-19's Public Health, Societal and Economical Impact, No 101003688)

\section{Availability of data and materials}

The code and data used to conduct these analyses are found at https:// github.com/jarvisc1/comix_covid-19-first_wave

\section{Ethics approval and consent to participate}

Participation in this opt-in study was voluntary, and all analyses were carried out on anonymised data. The study and method of informed consent were approved by the ethics committee of the London School of Hygiene \& Tropical Medicine reference number 21795

\section{Consent for publication}

Not applicable

\section{Competing interests}

WJE is a member of the Editorial Board of this Journal. Other authors declare that they have no competing interests.

\section{Author details \\ ${ }^{1}$ Centre for Mathematical Modelling of Infectious Diseases, Department of Infectious Disease Epidemiology, London School of Hygiene \& Tropical Medicine, Keppel Street, London WC1E 7HT, UK. ${ }^{2}$ Department of Psychological Medicine, King's College London, Denmark Hill, London, UK.}

\section{Received: 3 April 2020 Accepted: 17 April 2020}

\section{Published online: 07 May 2020}

\section{References}

1. ECDC. Situation update worldwide, as of 13 April 2020: ECDC; 2020. https:// www.ecdc.europa.eu/en/geographical-distribution-2019-ncov-cases. Accessed 13 Apr 2020
2. Jin Y-H, Cai L, Cheng Z-S, Cheng H, Deng T, Fan Y-P, et al. A rapid advice guideline for the diagnosis and treatment of 2019 novel coronavirus (2019nCoV) infected pneumonia (standard version). Mil Med Res. 2020;7:4.

3. Acaps M. COVID-19: government measures. 2020. https://www.acaps.org/ special-report/covid-19-government-measures. Accessed 25 Mar 2020.

4. Public Health England. Guidance on social distancing for everyone in the UK. gov.uk. 2020. https://www.gov.uk/government/publications/covid-19guidance-on-social-distancing-and-for-vulnerable-people/guidance-onsocial-distancing-for-everyone-in-the-uk-and-protecting-older-people-andvulnerable-adults. Accessed 28 Mar 2020.

5. Savanta. Savanta coronavirus daily tracker - 30th March. Savanta coronavirus daily tracker. 2020. https://cdn2.hubspot.net/hubfs/5043860/Covid-19\%2 Oassets/Full\%20data\%20set\%20PDFs/Savanta\%20Coronavirus\%20Daily\%2 OTracker\%20-\%2030th\%20March.pdf. Accessed 31 Mar 2020.

6. Atchison C, Bowman L, Eaton J, Imai N, Redd R, Pristera P, et al. Report 10: Public response to UK Government recommendations on COVID-19: population survey, 17-18 March 2020; 2020. https://doi.org/10.25561/77581.

7. Fancourt D. New study into psychological and social effects of Covid-19: UCL; 2020. https://www.ucl.ac.uk/news/2020/mar/new-study-psychologicaland-social-effects-covid-19. Accessed 25 Mar 2020.

8. YouGov. COVID-19 Public Monitor. YouGov. https://yougov.co.uk/topics/ health/explore/issue/Coronavirus. Accessed 31 Mar 2020.

9. Eames KTD, Tilston NL, Brooks-Pollock E, Edmunds WJ. Measured dynamic social contact patterns explain the spread of H1N1v influenza. PLoS Comput Biol. 2012;8:e1002425.

10. Hens N, Ayele GM, Goeyvaerts N, Aerts M, Mossong J, Edmunds JW, et al. Estimating the impact of school closure on social mixing behaviour and the transmission of close contact infections in eight European countries. BMC Infect Dis. 2009;9:187.

11. Prem K, Cook AR, Jit M. Projecting social contact matrices in 152 countries using contact surveys and demographic data. PLoS Comput Biol. 2017;13: e1005697.

12. Litvinova M, Liu Q-H, Kulikov ES, Ajelli M. Reactive school closure weakens the network of social interactions and reduces the spread of influenza. Proc Natl Acad Sci U S A. 2019;116:13174-81.

13. Zhang J, Litvinova $M$, Liang $Y$, Wang $Y$, Wang $W$, Zhao $S$, et al. Age profile of susceptibility, mixing, and social distancing shape the dynamics of the novel coronavirus disease 2019 outbreak in China. Epidemiology. 2020. https://doi.org/10.1101/2020.03.19.20039107.

14. Mossong J, Hens N, Jit M, Beutels P, Auranen K, Mikolajczyk R, et al. Social contacts and mixing patterns relevant to the spread of infectious diseases. PLoS Med. 2008;:5:e74.

15. R Core Team. R: a language and environment for statistical computing. 2017. https://www.R-project.org.

16. Dowle M, Srinivasan A. data.table: extension of 'data.frame'; 2020.

17. Wickham H. ggplot2: elegant graphics for data analysis. 2016. https:// ggplot2.tidyverse.org.

18. Office of National Statistics. Estimates of the population for the UK, England and Wales, Scotland and Northern Ireland mid-2018. 2019. https://www.ons. gov.uk/peoplepopulationandcommunity/populationandmigration/ populationestimates/datasets/ populationestimatesforukenglandandwalesscotlandandnorthernireland. Accessed 25 Mar 2020

19. Wallinga J, Teunis P, Kretzschmar M. Using data on social contacts to estimate age-specific transmission parameters for respiratory-spread infectious agents. Am J Epidemiol. 2006;164:936-44.

20. Klepac P, Kucharski AJ, Conlan AJK, Kissler S, Tang M, Fry H, et al. Contacts in context: large-scale setting-specific social mixing matrices from the BBC Pandemic project. Epidemiology. 2020. https://doi.org/10.1101/2020.02.16. 20023754.

21. Diekmann O, Heesterbeek JAP, Roberts MG. The construction of nextgeneration matrices for compartmental epidemic models. J R Soc Interface. 2010;7:873-85.

22. Pouillot R, Delignette-Muller ML. Evaluating variability and uncertainty separately in microbial quantitative risk assessment using two $\mathrm{R}$ packages. Int J Food Microbiol. 2010;142:330-40.

23. Riou J, Althaus CL. Pattern of early human-to-human transmission of Wuhan 2019 novel coronavirus (2019-nCoV), December 2019 to January 2020. Euro Surveill. 2020;25. https://doi.org/10.2807/1560-7917.ES.2020.25.4.2000058.

24. Imai N, Cori A, Dorigatti I, Baquelin M, Donnelly CA, Riley S, et al. Report 3: transmissibility of 2019-nCoV; 2020. https://doi.org/10.25561/77148. 
25. Read JM, Bridgen JRE, Cummings DAT, Ho A, Jewell CP. Novel coronavirus 2019-nCoV: early estimation of epidemiological parameters and epidemic predictions. MedRxiv. 2020; https://www.medrxiv.org/CONTENT/10.1101/202 0.01.23.20018549V2.abstract. Accessed 15 Apr 2020.

26. Zhao S, Lin Q, Ran J, Musa SS, Yang G, Wang W, et al. Preliminary estimation of the basic reproduction number of novel coronavirus (2019-nCoV) in China, from 2019 to 2020: a data-driven analysis in the early phase of the outbreak. bioRxiv. 2020. https://doi.org/10.1101/2020.01.23.916395.

27. Liu T, Hu J, Kang M, Lin L, Zhong H, Xiao J, et al. Transmission dynamics of 2019 novel coronavirus (2019-nCoV). bioRxiv. 2020. https://doi.org/10.2139/ ssrn.3526307.

28. Chinazzi M, Davis JT, Ajelli M, Gioannini C, Litvinova M, Merler S, et al. The effect of travel restrictions on the spread of the 2019 novel coronavirus (2019-nCoV) outbreak. MedRxiv. 2020. https://doi.org/10.1101/2020.02.09. 20021261.

29. Wu P, Hao X, Lau EHY, Wong JY, Leung KSM, Wu JT, et al. Real-time tentative assessment of the epidemiological characteristics of novel coronavirus infections in Wuhan, China, as at 22 January 2020. Euro Surveill. 2020;25. https://doi.org/10.2807/1560-7917.ES.2020.25.3.2000044.

30. Jung S-M, Akhmetzhanov AR, Hayashi K, Linton NM, Yang Y, Yuan B, et al. Real-time estimation of the risk of death from novel coronavirus (COVID-19) infection: inference using exported cases. J Clin Med Res. 2020;9. https://doi. org/10.3390/jcm9020523.

31. Zhuang Z, Zhao S, Lin Q, Cao P, Lou Y, Yang L, et al. Preliminary estimating the reproduction number of the coronavirus disease (COVID-19) outbreak in Republic of Korea from 31 January to 1 March 2020. medRxiv. 2020; https:// www.medrxiv.org/content/medrxiv/early/2020/03/10/2020.03.02.20030312. full.pdf. Accessed 15 Apr 2020.

32. Chong KC, Cheng W, Zhao S, Ling F, Mohammad KN. Monitoring disease transmissibility of 2019 novel coronavirus disease in Zhejiang, China. medRxiv. 2020; https://www.medrxiv.org/content/10.1101/2020.03.02.2002 $8704 v 1 . a b s t r a c t$.

33. Li Q, Guan X, Wu P, Wang X, Zhou L, Tong Y, et al. Early transmission dynamics in Wuhan, China, of novel coronavirus-infected pneumonia. N Engl J Med. 2020;382:1199-207.

34. Abbott S, Hellewell J, Munday J, Funk S, Group CNW, et al. The transmissibility of novel coronavirus in the early stages of the 2019-20 outbreak in Wuhan: exploring initial point-source exposure sizes and durations using scenario analysis. Wellcome Open Res. 2020;5:17.

\section{Publisher's Note}

Springer Nature remains neutral with regard to jurisdictional claims in published maps and institutional affiliations.

Ready to submit your research? Choose BMC and benefit from:

- fast, convenient online submission

- thorough peer review by experienced researchers in your field

- rapid publication on acceptance

- support for research data, including large and complex data types

- gold Open Access which fosters wider collaboration and increased citations

- maximum visibility for your research: over $100 \mathrm{M}$ website views per year

At BMC, research is always in progress.

Learn more biomedcentral.com/submissions 